\title{
Validity and Reliability of Timed Up and Go Test on Dynamic Balance in 3-5 Years Old Preschool Children
}

\author{
Lei $\mathbf{Y}^{1 *}$, Lam CKY², Lam MHS ${ }^{2}$, Peake $\mathrm{R}^{2}$, Wong ASW ${ }^{3}$, Flint SW4, Lee KY ${ }^{5}$, Li WHC ${ }^{6}$ and Ho $\mathrm{E}^{6}$ \\ ${ }^{1}$ School of Physical Education, University of Jinan, Shandong, China \\ ${ }^{2}$ Academy of Sport and Physical Activity, Sheffield Hallam University, UK \\ ${ }^{3}$ Research Support Unit, Vocational Training Council, Hong Kong \\ ${ }^{4}$ Leeds Beckett University, West Yorkshire, UK \\ ${ }^{5}$ Vocational Training Council, Hong Kong \\ ${ }^{6}$ School of Nursing, the University of Hong Kong, Hong Kong
}

\begin{abstract}
Objective: The purpose of this study was to investigate the validity and reliability of the Timed Up and Go Test (TUG) among normal 3-5 years old preschool children in Hong Kong.

Methods: Cross-sectional design was applied to this study. Sixty ( 30 female, 30 male) preschool children aged from 3 to 5 years old (mean age $=4.22 \pm 0.85$ ) from local normal preschool was recruited using convenient sampling to perform three dynamic balance tests: Timed Up and Go Test (TUG), Star Excursion Balance Test (SEBT) and the Pediatric Balance Scale Test (PBS). A simple self-administrative questionnaire survey was also conducted with their parents.

Results: Positive correlation $(r=0.74, p<0.05)$ was found between TUG results obtained at two time points when assessing the test-retest reliability. Moderated negative correlations were found between TUG and SEBT or PBS, which indicated children with longer reaching distance or higher PBS score tend to use shorter time to complete TUG.

Conclusion: TUG was a valid and reliable tool for assessing dynamic balance of preschool children aged between 3 and 5 years old. This can also be used for screening or early detection of developmental coordination disorder (DCD) for children aged 6 years old or younger.
\end{abstract}

Keywords: Timed up and go; Star excursion balance test; Pediatric balance test; Cerebral palsy; Community-dwelling people

\section{Introduction}

The health benefits of physical activity are extensively examined [1-10] and it is important to promote sport and physical activity [1116]. Meanwhile, fundamental movement skills are indispensable part in physical activity. Therefore, movement control is considered as important aspect in early-childhood development [17]. In children's physical perspective, movement development was the most important aspect. If children in their early-childhood failed to develop and refine the fundamental movement skill, they would be confused during adolescent and adulthood and felt difficult to achieve higher performance skills in future. Therefore, children should use an earlychildhood, roughly 3-8 years old, to learn and master the fundamental movement abilities. After that, specialized movement skill phrase started from 7 years old and the efficient performance based on the proper learning in fundamental movement skills on early child period [18]. Among different movement skills, balance of stability is most the important element on the child as it consists of static and dynamic balance. Since the development of dynamic balance are limited improving from 3 to 7 years old while basic static balance was developed before 3 years old [19], child should develop the basic balance as early as they can [18]. Developmental Coordination Disorder (DCD) usually occurred and identified in 6 to 12 years old school-aged children if they were imbalanced. Dynamic balance assessment tools in children are essential for earlier checking and assessing falling risk and determining the potential reasons of balance disorders [20]. Parents provide erect treatment as soon as by professional when children have unbalanced skill, problem in incoordination or some cerebellum problems in earlier year. Various movement performance assessment tools including SEBT and Körperkoordinations Test für Kinder (KTK) had been developed for specific target groups in early childhood population. However, this tools either too complex, involved too many equipment or require more skill. All these are difficult for 6 years old or younger to handle. Although TUG has been applied in dynamic balance studies in children with cerebral palsy and traumatic brain injury, study on TUG with normal preschool children in Hong Kong has not been reported. The purposes of this study were to investigate the validity and reliability of TUG in 3-5 years old normal preschool children.

\section{Methods}

\section{Participant}

A total of sixty preschool children were randomly selected from a traditional preschool in Hong Kong to participate in this crosssectional study. The inclusion criteria included: 1) well-being; 2) normal person; 3) able to communicate in Chinese and 4) able to follow the instructions of all tests. Children with physical and mental disability were excluded from this study. Ethics approval was obtained from the Faculty Research Ethic Committee (FREC) of the Sheffield

*Corresponding author: Lei Y, School of Physical Education, University of Jinan Shandong, China, Tel: +86 5318276 5454; E-mail: Spe_yangl@ujn.edu.cn

Received April 26, 2017; Accepted June 15, 2017; Published June 22, 2017

Citation: Lei Y, Lam CKY, Lam MHS, Peake R, Wong ASW, et al. (2017) Validity and Reliability of Timed Up and Go Test on Dynamic Balance in 3-5 Years Old Preschool Children. J Yoga Phys Ther 7: 266. doi: 10.4172/2157-7595.1000266

Copyright: (c) 2017 Lei Y, et al. This is an open-access article distributed under the terms of the Creative Commons Attribution License, which permits unrestricted use, distribution, and reproduction in any medium, provided the original author and source are credited. 
Hallam University prior conducting this study. Information sheets were given to each participant's parents in order to ensure they understand the procedures of this study. Consent forms were obtained from each participant's parent prior data collection. All participants had the right to withdrawn from the study at any time without penalty $[21,22]$.

\section{Timed up and go test (TUG)}

The timed up and go test (TUG) was first developed by Podsiadlo and Richardson in 1991 [23] and it was used to evaluate dynamic balance in elderly. In 2014, Nicolini-Panisson and Donadio [24] found that TUG was also a good assessment tool for functional mobility in the pediatric population. TUG contains a series of movements including sitting, standing, walking and postural control. Participant was first sat on a chair, after they heard the order "RUN", they required to rise up from a sitting position, walked for $3 \mathrm{~m}(\approx 9.8 \mathrm{ft})$ in straight line as fast as they can and turned back to the initial sitting position on same chair. TUG concerns the time it takes for the participant to complete the above task.

\section{Pediatric balance scale (PBS)}

Pediatric Balance Scale (PBS) was developed by Franjoine et al. in 2003 [25]. The purpose of PBS is to examine functional balance in the context of daily life's activities in the pediatric population. It contains 14 functional measured items, which are Sitting to standing, Standing unsupported, Standing to sitting, Sitting unsupported, Transfer, Standing with eyes closed, Standing with feet together, Standing with one foot in front, Standing on one foot, Turning $360^{\circ}$, Turning to look behind, Retrieving object from floor, Placing alternate foot on stool and Reaching forward with outstretched arm. The score level of each item will be recorded on a five-point likert scale (from 0 to 4), depending on the quality of performance. Total score ranged from 0 to 56 . Higher the score indicates better functional balance ability.

\section{Star excursion balance test (SEBT)}

Star Excursion Balance Test (SEBT) is simple test to assess a person's dynamic balance. To conduct SEBT, a "star", which formed by 4 lines and their centers are intercepted, is placed on the floor. The angle between each line is 45 degrees and the eight directions are named "Anterior", "Anterolateral", "Lateral", "Posterolateral", "Posterior", "Posteromedial", "Medial" and "Anteromedial". Participant stands a single-leg stance in one leg while other leg tried to reach as far as they can, the leg slightly touched on the scale for measuring the distance, then return to the starting position after each reaching trial.

\section{Procedures}

All participants' parents had signed the consent form and completed a short questionnaire, which focused on participants' demographical information and behaviors including age, gender, living district, sports interest and frequency of play sports, prior the study. Instruction and procedures of TUG, PBS and SEBT were described and demonstrated by well-trained researchers from the Vocational Training Council. In the TUG, participants were asked to perform to stand up from a seated position, walk forward for $3 \mathrm{~m}$ as quickly as possible, turn around, walk back to the chair and sat down. The time to complete the TUG was recorded using stopwatch. In the PBS, participants were asked to perform 14 daily activities and their performances were rated by the researchers. Modified version of SEBT was used for this study as the concentration of participants were lower than adult and the instruction of SEBT was difficult for them to understand. Therefore, the participants only required to perform the SEBT in three directions (anteromedial, medial and posteromedial). The length of each participant's legs was also measured and the relative distance in each direction for the scoring system was calculated. Participants allowed conducting trial run before the actual test took place for all test. The sequence of test order was randomized. The duration for each participant to complete the test was approximately $30 \mathrm{~min}$.

\section{Data analysis}

All the collected data was computed and analyzed using the IBM Statistical Package for the Social Sciences (SPSS) Statistics, version 20.0. Demographical information on participant was described using basic descriptive statistics, frequency and percentage for categorical data, and mean and standard deviation for numerical data. The relationships among TUG, PBS and SEBT were assessed using Pearson correlation coefficient. In order to determine the test-retest reliability, intraclass correlation coefficients were calculated. Significance of the correlation was also considered. P-value of $<0.05$ was considered as statistically significant. Descriptive statistics including mean and standard errors [26] of outcomes were reported.

\section{Results}

\section{Sport activities}

The mean age of sixty participants was 4.2 years old with standard deviation of 0.8 . Running $(n=48,80 \%)$ was the most popular sport activity, followed by cycling $(n=36,60 \%)$ and various kind of ball games $(n=31,52 \%)$. Most participants interested in more than one sport activity (excluding the Physical Education lesson in school). However, four participants (66.7\%) did not have any interested in sport. Twentytwo, eighteen and twenty participants' weekly frequency of conducting these sport activities were " 5 days or more", " $3-4$ days" and " $1-2$ day(s)", respectively.

\section{Validity}

TUG was significantly correlated with PBS and SEBT. Significant negative correlations were found between PBS and TUG. The correlation coefficient of PBS with first and second trials of TUG were $-0.721(\mathrm{p}<0.01)$ to $-0.511(\mathrm{p}<0.01)$. Negative correlations were also found between SEBT scores in six directions and time to complete the TUG test. The correlation coefficient ranged from -0.336 to -0.626 . The highest correlation coefficient was found between left leg anterolateral of SEBT and first trial of TUG test. However, in the second trial of TUG test, highest correlation coefficient was found in the right leg anteromedial. The correlation between TUG and SEBT is summarized in Table 1.

\section{Reliability}

For reliability testing, test-retest reliability was conducted. The mean (SD) time of first and second TUG trial was 5.19 (1.11) and 4.70 (0.90) s, respectively. The correlation between these two sets of time

\begin{tabular}{|c|c|c|c|c|c|c|}
\hline \multirow{2}{*}{ TUG } & \multicolumn{3}{|c|}{ Left leg } & \multicolumn{3}{c|}{ Right leg } \\
\cline { 2 - 7 } & Anteromedial & Medial & Posteromedial & Anteromedial & Medial & Posteromedial \\
\cline { 2 - 7 } & $\mathbf{r}$ (sig) & $\mathbf{r}(\mathbf{s i g})$ & $\mathbf{r}(\mathbf{s i g})$ & $\mathbf{r}(\mathbf{s i g})$ & $\mathbf{r}(\mathbf{s i g})$ & $\mathbf{r}(\mathbf{s i g})$ \\
\hline \multirow{2}{*}{ 1st } & $-0.626^{*}$ & $-0.537^{\star}$ & $-0.606^{*}$ & $-0.594^{*}$ & $-0.545^{*}$ & $-0.592^{*}$ \\
& $(0.000)$ & $(0.000)$ & $(0.000)$ & $(0.000)$ & $(0.000)$ & $(0.000)$ \\
\hline \multirow{2}{*}{ 2nd } & $-0.481^{*}$ & $-0.414^{\star}$ & $-0.486^{*}$ & $-0.523^{*}$ & $-0.336^{*}$ & $-0.469^{*}$ \\
& $(0.000)$ & $(0.001)$ & $(0.000)$ & $(0.000)$ & $(0.009)$ & $(0.000)$ \\
\hline
\end{tabular}

*correlation is significant at the 0.01 level (2-tailed)

Table 1: Correlation between timed up and go test (TUG) and star excursion balance test (SEBT). 
was significant $(\mathrm{p}<0.05)$ with $\mathrm{r}=0.740$. This suggests that the correlation between them was moderated and satisfactory.

\section{Discussion}

This was a first study to demonstrate TUG can be used as a dynamic balance assessment tool among 3 to 5 years old normal children. Past studies showed that TUG was a reliable tool in assessing dynamic balance with children with cerebral palsy $(\mathrm{r}=0.99,95 \% \mathrm{CI}=0.98-0.99)$ and community-dwelling elderly $(r=0.99)$ [22]. The result of TUG reliability in 3 to 5 years old preschool children are comparable in the current study of other population $[27,28]$. Result in this study agreed with some of the previous study $[29,30]$ which targeted population was children with cerebral palsy and elderly. This study found that the time recorded from TUG tests in two trials were similar on 3 to 5 years old children, but the performance of turning position with 3 meters distance were different. Through observation during TUG testing, some children turned in "big circle" with high running speed when they reached the turning point. On the other hand, some children decreased their running speed when they were near the turning point or the flying disc. Some children even ran quickly, stopped at the turning point and turned their bodies in 360 degrees. According to the guidelines of early childhood fitness ability progression program in preschool, different level of running abilities were captured during 3 to 5 years old children [18]. When children were three years old, they could run around the obstacles. When children were four years old, they could control the running direction technically and perform "sudden turn". When children reached the age of five years old, they could perform sudden stop, start and turn. Results showed negative correlation between SEBT and TUG test, which indicates children with longer reaching distance in SEBT tends to have shorter TUG time. However, it is difficult to implement the SEBT in clinical setting due to its complicated procedures. In 2003, Gribble and Herte [27] assessed the stability of chronic ankle with SEBT in three directions: anteromedial, medial and posteromedial in clinical setting. Result showed that moderate correlation between SEBT and TUG test. One of the limitations in this study was children aged three years old or younger can mastered their walking movement and enable to walk upstairs or downstairs. However, the movement of walking upstairs or downstairs was not assessed in this study. This study found that there was a moderated negative correlation between PBS and TUG test, which reflected the scores gained from PBS test was higher, the time used in TUG test was shorter, which suggested PBS was suitable for children development assessment. This result agreed with the finding from previous study conducted by Steffen et al. but with stronger correlation $(r=0.923)$ [28]. By comparing with other exist dynamic balance assessment tools, TUG was easier to administer as its instruction and command were simpler and duration of completing the test was shorter. This suggests that it is more suitable for 3 to 5 preschool children as their concentration was low and cannot receive too much command in a test or short period of time. Furthermore, TUG test could be used by parents and teachers for quickly screening on children's dynamic balance performance and early detection of developmental coordination disorder (DCD).

The strength of this study was to adopt a series of objective measures which reduce biases when compared with subjective measures [31-36]. However, sophisticated statistical analyses $[37,38]$ were not used due to the nature of data collected in this study, which may affect the validity of findings [39-41]. The limitation of this study also pertains to the short age range of the participants which would limit the generalizability of the findings. Significant differences in gross motoric development may also exist among the participants.

\section{Conclusion}

Timed Up and Go test was a valid and reliable tool for assessing dynamic balance of preschool children aged between 3 and 5 years old. This can also be used for screening or early detection of developmental coordination disorder (DCD) for children aged 6 years old or younger.

\section{References}

1. Cerin E, Lee KY, Barnett A, Sit CH, Cheung MC, et al. (2013) Walking for transportation in Hong Kong Chinese urban elders: A cross-sectional study on what destinations matter and when. Int J Behav Nutr Phys Act 10: 78.

2. Fung L, Lam MHS (2012) Effectiveness of a progressive stepping program on lower limb function in community dwelling older adults. J Exerc Sci Fit 10: 8-11.

3. Lam MHS (2016) Exercise game exhilarates the elderly: A challenge to traditional training. J Athl Enhanc 5: 1

4. Lam MHS, Cheung SY, Chow BC (2011a) The effects of Tai-Chi-Soft-Bal training on physical functional health of Chinese older adult. J Hum Sports Exerc 6: 540-553.

5. Lam MHS, Cheung SY, Chow BC (2011b) Effects of Tai Chi soft ball training on health-related quality of life of older adults with functional limitations. Asian J Gerontol Geriatr 6: 65-71.

6. Lam MHS, Kok EYL, Louie HTL, Lee KY (2014) External Chinese martial arts and health. In S. FONG (Ed.), Martial Arts for Health: Translating Research into Practice. CA, USA: OMICS Group Incorporation, pp.: 16-21.

7. Lam MHS, Leung AYM (2016) The effectiveness of health literacy oriented programs on physical activity behaviour in middle aged and older adults with type 2 diabetes: A systematic review. Health Psychol Res 4: 5595

8. Lam MHS, Leung AYM, Chan SSC (2011) Psychological and cognitive determinants of the health literacy on soon to be aged and older adults: A systematic review. Imanagers J Nurs 1: 46.

9. Lee KY, Lam MHS, Lam NKT, Sin HMY, Louis LHT (2014) Wrestling and Health. In S. FONG (Ed.), Martial Arts for Health: Translating Research into Practice. CA, USA: OMICS Group Incorporation, pp.: 38-41.

10. Lee KY, Lee PH, Macfarlane D (2014) Associations between moderate-tovigorous physical activity and neighbourhood recreational facilities: The features of the facilities matter. International Int J Environ Res Public Health 11: $2594-12610$

11. Li Ej, Lam MHS, Louie LHT, Li SSS (2012) An analysis on history and cultura background of Chinese Tai Chi Soft Ball. Asian Journal of Physical Education and Recreation 18: 27-30.

12. Lau PW, Lam MHS, Leung BW (2010) National identity and the Beijing olympics: School children's responses in Mainland China, Taiwan and Hong Kong. Proc Soc Behav Sci 2: 6729-6738.

13. Lau PW, Lam MHS, Leung BW, Choi CR, Ransdell LB (2012) The longitudina changes of national identity in mainland China, Hong Kong and Taiwan before, during and after the 2008 Beijing Olympics Games. Int J Hist Sport 29: 1281 1294.

14. Lau PW, Lam MHS, Leung BW (2011) The Beijing Olympics and expressions of national identity in China, Taiwan and Hong Kong. The Olympics in East Asia: Nationalism, Regionalism and Globalism on the Center Stage of World Sports 147.

15. Ho G, Yiu EYM, Lam MHS (2016) The Hong Kong games in the eyes of loca sports and recreation students. Int J Hist Sport 33: 1209-1225.

16. Lam MHS (2010) management evaluation of the healthy athlete program of 2007 Shanghai Special Olympics World Summer Games. Asian Journal of Physical Education and Recreation 16.

17. Wong SS, Ho M, Ho WK, Kwong CM (2007) Kindergarten health rewards program: Practice guidelines of promotion in child motor ability [ebook]. Hong Kong: Centre for Health Education and Health Promotion.

18. Gallahue DL, Cleland-Donnelly F (2007) Developmental physical education for all children. USA: Human Kinetics.

19. Spodek B, Saracho ON (2014) Handbook of research on the education of young children, Routledge.

20. Community Sports Committee (2012) Report of the Advisory Committee for the 
Citation: Lei Y, Lam CKY, Lam MHS, Peake R, Wong ASW, et al. (2017) Validity and Reliability of Timed Up and Go Test on Dynamic Balance in 3-5 Years Old Preschool Children. J Yoga Phys Ther 7: 266. doi: 10.4172/2157-7595.1000266

Healthy Exercise for All Campaign - Physical Fitness Test for the Community [online].

21. Kumban W, Amatachaya S, Emasithi A, Siritaratiwat W (2013) Five-times-sitto-stand test in children with cerebral palsy: Reliability and concurrent validity. NeuroRehabilitation 32: 9-15.

22. Shumway-Cook A, Brauer S, Woollacott M (2000) Predicting the probability for falls in community-dwelling older adults using the Timed Up and Go Test. Phys Ther 80: 896-903.

23. 23 Podsiadlo D, Richardson S (1991) The timed "Up and Go": A test of basic functional mobility for frail elderly persons. J Am Geriatr Soc 39: 142-148.

24. Nicolini-Panisson RD, Donadio MV (2014) Normative values for the timed 'Up and Go' test in children and adolescents and validation for individuals with Down syndrome. Dev Med Child Neurol 56: 490-497.

25. Franjoine MR, Gunther JS, Taylor MJ (2003) Pediatric balance scale: A modified version of the berg balance scale for the school-age child with mild to moderate motor impairment. Pediatr Phys Ther 15: 114-128.

26. Lee KY, Cerin E (2014) Standard Errors. In A.C. Michalos (Ed.), Encyclopedia of Quality of Life and Well-Being Research. Netherlands: Springer, pp: 63196320.

27. Gribble PA, Herte J (2003) Considerations for normalizing measures of the Star Excursion Balance Test. Meas Phys Educ Exerc Sci 7: 89-100.

28. Steffen TM, Hacker TA, Mollinger L (2002) Age- and gender-related test performance in community-dwelling elderly people: Six-minute walk test, berg balance scale, timed up and go test and gait speeds. Phys Ther 82: 128-137.

29. Gribble PA, Hertel J (2003) Considerations for normalizing measures of the star excursion balance test. Meas Phys Educ Exerc Sci 7: 89-100.

30. Kumban W, Amatachaya S, Emasithi A, Siritaratiwat W (2013) Five-times-sitto-stand test in children with cerebral palsy: Reliability and concurrent validity. NeuroRehabilitation 32: 1, 9-15.
31. Cerin E, Chan Kw, Macfarlane DJ, Lee KY, Lai Pc (2011) Objective assessment of walking environments in ultra-dense cities: development and reliability of the Environment in Asia Scan Tool-Hong Kong version (EAST-HK). Health Place 17: $937-945$.

32. Cerin E, Lee KY, Barnett A, Sit CH, Cheung Mc, et al. (2013) Objectivelymeasured neighborhood environments and leisure-time physical activity in Chinese urban elders. Prev Med 56: 86-89.

33. Lee KY, Lam MHS, Deng Y (2017b) Measuring post-concussive activity levels of patients: Step count or activity intensity? JAMA Pediatr 171: 493-494.

34. Lee KY, Lam MHS, Lee PH (2017) Distance From home to the nearest tobacco outlet may not reflect the true accessibility. JAMA Intern Med 177: 287-287.

35. Lee KY, Macfarlane D, Cerin E (2013a) Objective evaluation of recreational facilities: Development and reliability of the recreational facility audit tool. J Park Recreat Admi 31: 92-109.

36. Lee KY, Macfarlane DJ, Cerin E (2013b) Comparison of three models of actigraph accelerometers during free living and controlled laboratory conditions. Eur J Sport Sci 13: 332-339.

37. Lee PH, Tse AC, Lee KY (2016)A new statistical model for the day reconstruction method. Int J Methods Psychiatr Res.

38. Deng Y, Lee KY, Lam MHS, Lee PH (2016) Understanding socio-behavioral mitigators of depressive symptoms among US young adults. Behav Med 42 217-226.

39. Lee KY, Lam MHS, Deng Y (2017a) Interventions for anxiety and depression in conflict-affected areas. JAMA 317: 1376-1376.

40. Lam MHS, Chow BC, Cheung SY, Lee KY, Li WHC, et al. (2017) A systematic review of recreation therapy for depression in older adults. J Psychol Psychother 7: 2161-2487.

41. Lam MHS, Tung K, Man DP, Lee KY, Lei Y, et al. (2017) Examining lower limb injuries among male amateur soccer player. J Yoga Phys Ther 7: 264.
Citation: Lei Y, Lam CKY, Lam MHS, Peake R, Wong ASW, et al. (2017) Validity and Reliability of Timed Up and Go Test on Dynamic Balance in 3-5 Years Old Preschool Children. J Yoga Phys Ther 7: 266. doi: 10.4172/21577595.1000266

\section{OMICS International: Publication Benefits \& Features}

Unique features:

- Increased global visibility of articles through worldwide distribution and indexing

- Showcasing recent research output in a timely and updated manner

Special issues on the current trends of scientific research

Special features:

$700+$ Open Access Journals

$50,000+$ editorial team

Rapid review process

Quality and quick editorial, review and publication processing

Indexing at major indexing services

- Sharing Option: Social Networking Enabled

- Authors, Reviewers and Editors rewarded with online Scientific Credits

- Better discount for your subsequent articles

Submit your manuscript at: http://www.omicsonline.org/submission/ 